\title{
أبعاد الجريمة فى التعليم الثانوي الفني
}

إعـــــداد

د/ ننسى أحمد فؤ اد

مدرس أصول التربية

كلية التربية بقتا - جامعة جنوب الوادى
أ.م.د/ محمد النصر حسن

أستاذ أصول التربية المساعد ورئيس القسم كلية التربية بقنا - جامعة جنوب الوادى

$$
\begin{aligned}
& \text { أسماء حسنى محمود أحمد } \\
& \text { باحثة ماجستير } \\
& \text { بكلية التربية بقتا - جامعة جنوب الوادى }
\end{aligned}
$$

$5 r \cdot 12$ 
المستخلص: - (الم:

الجريمـة من المشكلات الاجتماعية التي عرفها المجتمع الإنساني في كافة عصوره وعلى اختلاف نظمه وأنثاله، وكانت موضوع اهتمام المفكرين كل حاول أن يبدى فيها

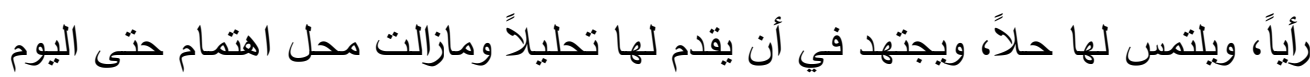
وإلى أن يشـاء الله ـ ويتتاول هذا المقال أبعاد الجريمـة في التعليم الثانوي الفني وهو التها المرحلة الوسطى من سلم التعليم بحيث يسبقه التعليم الأساسي ويتلوه التعليم العالي ،

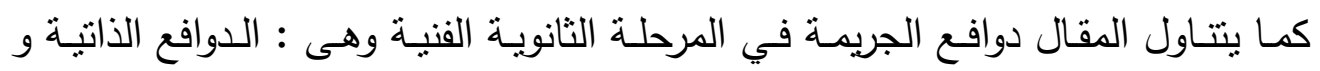
الاضطرابات الثخصية لطلاب المدرسة الثانوية الفنية وهنالك بعض الدوافع التي ترجع إلي الأسرة. وكذللك ترجع بعض الدوافع إلى جماعة الرفاق وشبكة الاتصالات الدولية وأيضاً وسائل الاعلام.

الكلمات الافتتاحية : الجريمة - التعليم الفنى الثانوي - مشكلات التعليم 
أبعاد الجريمة فى التعليم الثانوي الفني

إسماء حسنى محمود أحمد

\section{Dimensions of crime in secondary technical education}

Prof.Dr. Mohamed EI Nasr Hassan

Dr. Nansy Ahmed Fouad

\section{Asma Hosni Mahmoud}

\section{Abstract:}

The crime is one of the social problems that human society has known in all its ages and its different systems and forms. It has been the subject of the attention of all intellectuals who tried to show an opinion, seek solutions and strive to present it with analysis and interest until today and until God wills. This article deals with the dimensions of the crime in secondary technical education, which is the middle stage of the education ladder, preceded by basic education and followed by higher education. The article also examines the motives of crime in the technical secondary stage: self- motivation and personal disturbances of high school students. . Some of the motives are also attributed to the Comrades, the International Telecommunications Network and the media.

Key Words : The Crime - Secondary technical education Education Problem 
عرفت البشـرية منذ عصـورها السحيقة صـنوفاً مـن الانحراف والسلوك الإجرامي وتحدث التاريخ عن أساليب لإعلام الناس بما هو مرغوب ، وما ليس بمرغوب، وفى الوقت نفسه سجل التاريخ من السلوك ما هو مستحسن، وما ليس هو متحسن فضـلاً عـن أسـاليب الـردع والمواجهـة، فالجريمـة عُرفت منـذ فجر البشـرية، وورد ذكرهـا في مختلف الأديان والشرائع والأعراف والقوانين، وقد درست الجريمة قديماً وحديثًا من نواح متعددة، وزوايا مختلفة ، مما يترتب عليه تعدد وجهات النظر بشأنها.

حيـث يعيش العـالم اليوم حضـارة ماديـه هائلــة وتقدما مـذهلاً في مجـال العلـوم الطبيعيـة والتكنولوجيـة هذا التقدم يعد سـلاحا ذا حدين فهو مـن ناحيـة أدى إلى رفع مستوى رفاهية الفرد وذلك لما أوجده التقدم العلمي من أجهزه وأدوات ومعدات ساعدت بشكل ملحوظ في توفير وقت الفرد وجهده وقامت نيابة عنه بأعمال كثيرة كان يصعب عليه القيام بها إلا أن هذا التقدم من ناحية أخرى أدى إلى إكساب الحياة طابعها السريع وأصبح الكثير من الناس لا يرى إلا مصلحته الخاصة غير عابئ بمصالح الآخرين . وبالتالي قل حرص الإنسان على أخيه الإنسان وتراجعت الروحانيات لتحل محلها

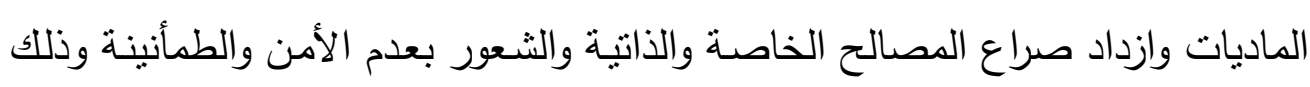
لأن البيئة الحضرية تؤدى في حالات كثيرة إلى تراخى الضوابط الاجتماعية المباشرة كما توفر فرصا أكثر وأفضل للسلوك الإجرامي وعليه يمكن القول بأن البيئة الحضرية تمهـد للفعـل الإجرامسي الـذي يقع في حالـة تـوافر ظـروف أخـرى نفسيه واجتماعيـه واقتصاديه وتثقافيه.

والجريمة نسبية تختلف من مجتمع لأخر وتختلف من وقت لأخر فما يعتبر جريمة

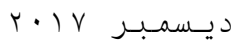


أسماء حسنى محمود أحمد

في مجتمـع قد لا يكـون كذللك في مجتمـع آخـر في نفس الوقت، فمـلاً في الوقت

الحاضر وفى بعض المجتمعات الأوربيـة نجد البغاء والجنسية المثليـة والإجهاض إذا كان برغبة المرأة لا يعتبر جرائم وفى نفس الوقت يعتبر جرائم يعاقب عليها القانون في مصر كما تختلف من وقت لأخر وأد البنات في الجاهلية لم يكن يعتبر سلوكا انحرافيا في ذلك الوقت بينما اعتبر جريمة بعد ظهور الإسـلام في الجزيرة العربية .

تعتبر المرحلة الثانوية الفنية من المراحل الدراسية الهامة للطلاب ، والطالب في

هذه المرحلة يمر بفترة حرجة من مراحل النمو وهي مرحلة المراهقة حيث تظهر فيها العديد من المشاكل والميول والاتجاهات والرغبات والثهوات والحاجات فإذا لم يتم فيها توجيههم من قبل الآباء والمعلمين توجيهاً سليماً في ظل إطار شرعي وتربوي مرن بعيداً عن التهاون والتساهل والتخلي عن المبادئ والمثل والقيم وبعيداً عن التصرفات العصبية المنتددة فإن الثباب في هذه المرحلة يضبعون مما يؤدي بهم إلى الانحطاط والفثل وعدم القدرة على مواجهة منطلبات الحياة ومشاكلها ومن ثم إلى الوقوع في

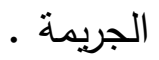

فالمدرسة مع نهاية القرن العثرين افتقدت دورها التربوي المتمثل في تحقيق النضـج الاجتماعي للطلاب من خلال تتمية العقل والجسم والنفس لتحقيق أفضل مستوى ممكن من الكيف بفاعلية مع الواقع الاجتماعي فظهرت الكثير من الانحرافات بين الطلاب داخل المدرسة منها التطرف الديني والعنف وتعاطي المخدرات والبلطجة

والجريمة كمشكلة اجتماعية شغلت أذهان الناس عامة على مر الأجيال واهتم بها الفلاسفة ورجال الدين وعلماء النفس والمصلحون الاجتماعيون في مختلف العصور وذلك بغرض الحد من خطورتها والتخفيف من آثارها الضارة في المجتمعات الإنسانية 
أسماء حسنى محمود أحمد

أو القضاء عليها إن كان ذللك ممكناً للمحافظة على كيان المجتمع وبقائه وأمنه ورفاهيته واتخذوا في ذلك سبل مختلفة للتعرف على أسبابها ووضع الحلول لمقابلتها وعلاجها واذا أردنا علاجها ومنعها والوقاية منها فعلينا أن نتفهم أسبابها أولاً ونعمل على علاجها حتى تختفي أعراضها ، وسوف تتتاول الباحثة فيما يلى أهم أبعاد الجريمة فى التعليم الثانوى الفنى

\section{أولاً :أبعاد الجريمة فى التعليم الثانوى القنى :}

تعد مشكلة ارتفاع معدلات الجريمة على المستوى العالمي من أكبر المشكلات ذلك أن طرق حل المشكلات الاقتصادية، والتخلف العلمي قد أتضح إلى حد كبير في حين لم تتضـح طرق الحل لمشكلة ازدياد الجرائم، فلم تعط الحلول المقترحة عند تجريبها النتيجة المرجوة وتكمن خطورة تلك المشكلة في تهديد أمن الأفراد واقتصادهم ومن هنا فإن ظاهرة الجريمة تتعكس على الطلاب والمدرسة ، وتتجلى خطورتها فى عدة نواحى : من

ا - تدمير أثات المدرسة وأبنيتها وتشوبهها .

r- فثل بعض الطلاب فى استكمال فرص تعليمهم •

$$
\begin{aligned}
& \text { r- الهروب من المدرسة . } \\
& \text { ع - التسرب الدراسى . }
\end{aligned}
$$

0- الخروج عن سلطة المعلمين أو الإدارة المدرسية . ج- زيادة نسبة الانحرافات السلوكية منل : تعاطى المخدرات ، والسرقة ، والغش . • - الخروج عن سلطة الوالدين - - - ض - ضعف القيم الأخلاقية والدينية . 
9- انتشار ظاهرة الغش الجماعى ·

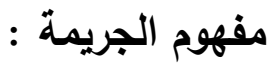

الجريمة من المشكلات الاجتماعية التي عرفها المجتمع الإنساني في كافة عصوره وعلى اختلاف نظمه وأنشاله، وكانت موضوع اهتمام المفكرين كل حاول أن يبدى فيها رأياً، ويلتمس لها حلاً، ويجتهد في أن يقدم لها تحليلاً ومازالت محل اهتمام حتى اليوم وإلى أن يشاء الله .

وتعرف الجريمـة بأنها : الجريمـة هي سلوك غير سوى معاد للمجتمع من أجل إثباع لغريزة إنسانية بطريقة لا اجتماعية .

والجريمة تشكل خطرا على المجتمع، ولذا ينظر اليها باعتبارها مرض اجتماعي في حين يذهب " دور كايم" الى ان الجريمـة تكاد تكون الظـاهرة الوحيدة التي تتطوي بصـفة لا تقبـل الثـلك على جميـع أعـراض الظـاهرة السـليمة، ومعنى ذلـك أن إدخـال الجريمـة ضـمن الظواهر الاجتماعيـة السليمة لبس معنـاه أنها ظـاهرة لا يمكن تلافيها فحسب ، ولكن معنى ذلك أيضاً أن الجريمة عامل لابد منه لسلامة المجتمع وأنها جزء لا يتجـزأ مـن كـل مجتمـع سـليم إذن فالجريمــة مرتبطــة بالثـروط الاساسـية للحيـاة الاجتماعية وهى بذلك ظاهرة مفيدة .

\section{مفهوم التعليم الثانوى الفنى :}

تعد المرحلة الثانويـة من أهم مراحل الدراسة التي يمر عليها الطالب خلال مسيرته الدراسية ، ولأهميـة هـذه المرحلـة خطورتهـا فـإن الجهات المعنيـة بالتربيـة توليهـا كل الاهتمام ، من حيث أن التعليم الثانوي عامل قوى ، تعتمد عليه الأمم في بناء مستقبلها 
وتوليـه السياسـة التعليميـة عنايـة كبيـرة ، حيـث أنسه خطـوة مهمـة وقويـة على طريـق المستقبل ، فطـلاب هذه المرحلـة هـ النبـت الأول في تكوين الفكر بالنسبة للقيـادات العلميـة ، ولذا كان الاهنمام بالطالب من جميع النواحي التربويـة والعلميـة ، والأنثطة الثقافية والرياضية ، من أهم الأمور في هذه المرحلة الحساسة . وقد عرف سعد الدين : المرحلة الثانوية بأنها : " المرحلة الوسطى من سلم التعليم بحيث يسبقه التعليم الأساسي ويتلوه التعليم العالي " . ويرى السيد : أن طالب المرحلة الثانوية يمنل الفترة العمرية من ع ا ـ 1 ا سنة . ثانيا: دوافع الجريمة فى المرحلة الثانوية القنية: الدوافع التي تسهم في رفع درجة الجريمة لدى طلاب المدرسـة الثانويـة الفنيـة هي دوافع متعددة ومتداخلة ، ولكن هناك بعض العوامل التي تسهم بدرجة أكبر من غيرها في إحداث السـوك الإجرامس، ومـن هذا المنطلق جـاء التركيز على بعض الدوافع الاجتماعيـة مثل : الأسـرة ، فهي المؤسسـة الاجتماعيـة الأولى التي تسـتقبل الطفل ، وتعد الوعاء التربوي الأول الذى تتشكل من خلالهـ شخصيته الاجتماعية، وهى بهذا تمارس عمليات تربوية هادفة لتحقيق نمو الفرد .

ويـأتي دور وجماعـة الرفاق، والانترنـت ووسـائل الاعـلام والتليفزيـون والفضـائيات باعتبارهما المؤسسات الاجتماعية التي تستقبل الطفل، حيث يتأثر بهم، ومـع استمرار ذلك تقوى الروابط والمشـاركات، وتتكون اتجاهاته إما إيجاباً وإما سلباً ، وبالتالي تكون سـلوكياته إمـا مندمجـة مـع المجتمع ومتققـة مـع سـلوكياته أو تتكـون لديـه السـلوكيات

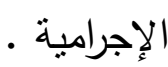

فإن ذلك يعنى أن هناك مؤسسات اجتماعية أخرى غير الاسرة والمدرسة لها تأثنرها 
/أسماء حسنى محمود أحمد

في إكساب الطالب سلوكيات اجرامية أو عدم إكسابه إياها، ومن هذه المؤسسات وسائل الاعـلام والانترنــت والتليفزيـون والفضــائيات ، والهـاتف المحمـول وجماعـة الرفـاق ، باعتبارهما من المؤسسات الاجتماعية التي لها ارتباط وثيق بحياة الحدث منذ ولادته ، وحتى مرحلـة الكبر ، وقد يكون السلوك الإجرامسي مـن النوع المرضـى أبي يرجـع إلى مرض أو علة لدى الثخص الذى يمارسه ، وكانت الإحصاءات قد أثنتت وجود علاقة بين الجريمة والحالة الاقتصادية التي يعيشها بعض الأفراد . ويتضح مما سبق أن هناك عوامل متعددة ومنشابكة تسهم في ايجاد السلوكيات العنيفة، وارتفاع وتيرتها في المجتمع ، وفيما يلى تعرض الباحثة أهمها: (1) (الدوافع الأتية وهى الدوافع التي تجد مصدرها في الفرد ذاته ، ومن أهم الدوافع الذاتية المؤدية إلى الجريمة ما يلى : البعى - - الثعور المتزايد بالإحباط . -

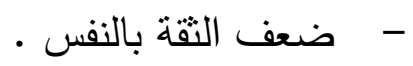
- طبيعة مرحلة البلوغ والمراهقة . - - الاضطرابات الانفعالية والنفسية وضعف الاستجابة للمعايير الاجتماعية . - - الرغبة في الاستقلال عن الكبار والتحرر من السلطة الضاغطة عليهم ، والتي تحول دون تحقيق رغباتهم • - عدم المقدرة على مواجهة المشكلات التي يعانى منها الفرد . ومن العوامل الذاتية التي تسهم في تكوين السلوكيات الاجرامية كذلك : الرغبة في الحصول على ممنوعات أو محرمات أو أشياء يصعب قبولها . العجز عن إقامة علاقات اجتماعية صحيحة . 


$$
\text { الشعور بالفشل أو الحرمان من العطف . }
$$

عدم قدرة الفرد على التحكم في دوافعه العدوانية .

ارتفاع نسبة الأنا ، فالإجرام هو صورة الأنا والأنانية في الفرد ، وأن العلاقة بينهما مطردة ، فكلما زادت الأنا زادت الجريمة ، فالتهمة الشخصية كالوصف بالنذالة أو التحقير ، أو التقليل من شأن الآخر ، كلها عوامل تزكى الأنا العدوانية عند الفرد وتزيد من حساسيتها ، التي لابد حين تتواجد عوامل ومحفزات أن تنتيقظ لدى أول دافع باتجاه الجريمة أو السلوك الإجرامي • الإدمان على المخدرات: ويعد الإدمان على المخدرات من الأسباب التي تؤدى إلى الجريمة ، لأن المدمن يعانى من اضطرابات نفسية هي التي دفعته إلى الإدمان ، ومن هذه الاضطرابات : عدم القدرة على التكيف مع الواقع • عدم الثعور بالاطمئنان والقلق والاضطراب النفسي • ضعف الوازع الديني: الدين يهذب السلوك ويقومه ، ويكسب الفرد قيماً سامية رفيعة تتأى به عن السلوكيات المنحرفة، ومن بينها الجريمة ، لأنه يغرس في الفرد قيم الإيثار والحب والتسامح والرفق والرحمة ، وكلها قيم تباعد تماماً بين الفرد والإجرام الذى يبنى على الأنانية ، وجوهره ضد الرفق والرحمة والتسامح . وقد أثنتت الدراسات كدراسة ( أبو الخير ، والعصرة ) "أن الانحراف والجريمة يزيدان كلما قلت ممارسة الفرد للفروض الدينية ، وتقسير هذه العلاقة لا يحتاج إلى تقصيل إذ إن التعاليم الدينية تغرس في نفس الفرد قواعد الأخلاق ، وتحثث على السلوك الثريف ، وتبعده عن دروب الزيغ والإجرام والانحراف" . (Y) الاضطرابات الثخصية لطلاب المدرسة الثانوية القنية 


\section{1. تعريف اضطرابات الشخصية: \\ (أ) تعريف علم النفس:}

يعرف الاضطراب في موسوعة علم النفس والتحليل النفسي بأن الاضطراب يعنى لغوياً الفساد أو الضعف وهو لفظ يستخدم في مجال علم النفس بصفة عامة وفى مجال علم الـفس الإكلينيكي بصـفة خاصــة وكذا في الطـب النفسـي. وهـو يطلـق على الاضطرابات التي تصيب الثخصية من ناحية التفكير أو الانفعال أو السلوك، ويعنى سوء نوافق الفرد مع ذاته، أو مع الواقع الاجتماعي الذى يحيا فيه. إضـافة إلى العديد من المظاهر - الأخرى - التي تصيب الشخصية من ناحية فقدان اتزانها وثباتها الانفعالي أو تمييزها بالعديد من السمات التي تميز كل نمط من أنماط اضطرابات الثخصية. (ب) تعريف الطب النفسي: (1) اضطرابات الشخصية نوع مـ الاضطرابات تصبح فيـه سـات الثخصية غير مرتبة ولا متوافقة، وتسبب لصساحبها خلل ملحوظ في أداء وظائفه أو الشعور بالمعاناة، وتظهر على هؤلاء المرضى أنماط متأصلة وثابتة وغير منوافقة في التعامل مع البيئة وإدراكها وفى التعامل مع أنفسهم وفى تصورهم لذاتهم. (Y) تعـرف اضـطرابات الثخصـية بأنهـا أنــاط متصـلة وغيـر متوافقـة مـن السـلوك المتأصل والمتغلغل في نسيج الشخصية، والتي لا ترجع إلى اضطرابات المحور الأول أو الثالث ، أو اضطرابات نتتج عن مشكلات تتعلق بدور الشخص في ثقافته ـ وهذه الفئة من الأمراض تعود إلى اضطرابات سمات الثخصية ، وليست تغيراً طارئاً عليها. وقد يتخذ اضطراب السمة مظهراً سلوكياً، أو انفعالياً، أو معرفياً، أو حسياً، أو دينامياً. r. تصنيف اضطرابات الشخصية: 
/أسماء حسنى محمود أحمد

الطائفة (أ) : وتضم أنواع اضطرابات الثخصية التي تتصف بالغرابة والثذوذ، ويندرج تحت هذه الطائفة اضطرابات الثخصية البارانويدية، وشبة الفصامية، والفصامية النوع. الطائفة (ب) : وتضم هذه الطائفة كافة الثخصيات المضطربة والتي يغلب على

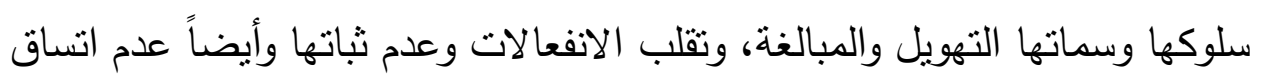
الانفعالات مع الموقف ويندرج في هذه الطائفة اضطرابات الثخصية النرجسية، والمناهضة أو المضادة للمجتمع ، والثخصيات البينية. الطائفة (ج) : ويغلب على الثخصيات التي تتدرج في هذه الفئة ظهور القلق والمخاوف بصورة واضحة. وتضم هذه الطائفة الثخصيات الآتية المتجنبة، الاعتمادية، الوسواسية القهرية. r. العلاقة بين السلوك الإجرامي لدى طلاب المدرسة الثانوية الفنية والاضطرابات الشخصية:

(أ) السلوك العدواني كسمة أساسية في مجموعة من الاضطرابات هي: 1- الاضطراب الانفجاري المتقطع. r- اضطراب الانفجاري المنفرد.

ب- اضطراب السلوك العدواني غير المتكيف اجتماعياً. ع- اضطراب المسلك العدواني المتكيف اجتماعياً. 0- اضطراب الثخصية العدوانية المعادية للمجتمع. 1- اضطراب الثخصية الحدية.

(ب) السلوك العدواني كسمة مصاحبة في مجموعة من الاضطرابات هي: ا - اضطراب تعاطى العقاقير والمخدرات. r- الاضطرابات العقلية العضوية. 


$$
\begin{aligned}
& \text { r- التأخر العقلي. } \\
& \text { ع - اضطراب نقص الانتباه. } \\
& \text { 0- الذهان التفاعلي بعيد المدى. } \\
& \text { 7- الاضطراب الفصامي. } \\
& \text { V - الاضطراب الفصامي الوجداني. } \\
& \text { 1- الاضطراب البارانويدى. } \\
& \text { 9- اضطراب كرب ما بعد الصدمة. }
\end{aligned}
$$

(ج) السلوك العدواني كسمة غير غالبة في مجموعة من الاضطرابات هي:

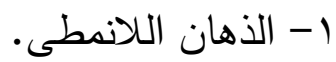

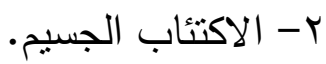
r-اضطراب عسر المزاج. ع - اضطراب المزاج الدوري (هوس - اكتئاب أو العكس).

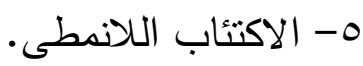
7- اضطراب الثخصية البارانويدية.

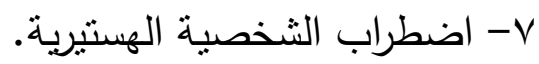
1- اضطراب الثخصية فصامية الطبع. 9- الثرود نفسى المنشأ. • 1- اضطراب التوافق مع اختلال المسلك. (r) المشكلات الاسرية لطلاب المدرسة الثانوية الفنية: ومن الواضـح أن تتشئة الأطفال في مجال الصـراعات العائلية والتوترات قد تجعل الطفل منحرفاً في المستقبل، فالأب الذى يعانى من المتاعب في عمله يفرغ ما يعانيـه 
أسماء حسنى محمود أحمد

على زوجته وأبنائه للتخلص من التوتر ، وبؤدى هذا الموقف الى عواقب وخيمة على الأبنـاء، وكثيـراً مـا نـلاحظظ أن الطفل الناشــ في مجـال الصـراعات والتوترات يصـب عدوانـه على الـدمى، فـإذا عنفت الأم طفلتها فـان الطفلـة تمسـك بدميتها وتعنفها لأن الافراغ والتقليد لدى الطفل أيضاً. وترى الباحثة : بـأن الطالب في عصـرنا الحاضـر بتمتع بجميع وسـئل الراحـة والترفيهية التي تساعد على تطور نمو العقلي وتوسع معارفه ، ولكن من المؤسف جدا هو غياب دور الاسرة في وقاية الطلاب من الجريمـة مدا يؤثز في سلوكيات الطلاب و يؤثر على شخصيتهم ووقوعهم في الجربمة .فالبيت الذي بتمتع فبه الطلاب بالحوار الديمقراطي الذي يتسم بـالاحترام والأخلاق بكون خير موقع للطالب على المستوى الانفعالي، وعلى العكس من ذللك، فان البيت الذي تتبعث فيه الخلافات العائلية، وتشيع فيه روح الأنانية والحقد يؤدي إلى الانحراف مما يدفع ذلك إلى سلوك غير مقبول في المجتمع ويبعث لدى الطالب القلق والخوف ، والميل إلى العزلة، والانطواء وعدم القدرة على تبادل العواطف مع غيره من الأفراد ، مما يصبح عنصرا غير فعال في المجتمع وبالتالي الى ارتكابـه للجربمـة.ومن هنـا نجدان غيـاب دور الأسـرة في تربيـة الأبنـاء لـه تأثير غلى شخصية الطلاب وبؤدى بهم الى ارتكاب الجريمة . العلاقة بين السلولو الإجرامي والمشكلات الاسرية: إن وجود الحدث في أسـرة معينة هو السبب إل تكوين شعورة الأول بالانتمـاء إلى جماعـة أوليـة هو جزء ضـروري منها، وهذا لا شـك يقوده إلى تحقيـق انتمـاءات أخرى لجماعات أولية أخرى. ولذلك تعتبر الأسرة من أهم العوامل البئية المسببة للانحراف وهى العامل المشترك الذى يقف عنده كل باحث في طبيعة الجنوح. لذلك فالأسـرة دور كبيـر في ميـل الحدث أو عزوفهه عـن السـوك الإجرامس، فـاذا 
/أسماء حسنى محمود أحمد

كانت الأسرة سليمة ومتماسكة. يسود أفرادها الوئام والسـام. وإذا كان كلاً من الأبوين متمتعاً بصحة جيدة، وكان دخل الأسرة مناسباً يكفى لأفرادها ويوفر لهم حد أدنى من الرخاء، فإن ذلك يعتبر داعباً الى اتخاذ الأبناء مسلكاً سليماً، أما إذا تفكلك كيان الأسرة وتصــــ، ودب الخـلاف والبغض والثـجار بـين أعضـاءها، أو كـان أحـد الابـوين أو كلاهما يعانى وطأة مرض عضوي أو نفسى أو عقلي، أو كان دخل الأسرة ضئيلاً لا يكاد يكفل مـا يقيم من الأولاد، كان ذللك دافعـاً إلى انتهاج أبنائها الإجـرام. والتهكلك الأسرى قد يكون تفككاً مادياً، وقد يكزن معنوياً وسوف نلقى الضوء فيما يلى على كلا النوعين لإيضـاح تأثثره على ظاهرة الإجرام، ثم نوضـح أثر المسكن غير الملائم في السلوك الإجرامي.

\section{( ( ) دوافع ترجع الى جماعة الرفاق:}

هي أحد المصـادر المههـة والمفضلة عند المراهقين للاقتداء واستقاء الآراء والأفكار، حيث أن الفرد وهو يتفاعل مـع أصدقائه فإنه يراوح نفسه في أنه يميل أولاًٌ إلى العتاب والتصـافى، ثم يعرج مباشـرة إلى المقاطعة وهى تؤدى احياناً الى التفكير في الاجرام في تفاعله مـع أصدقائه، ولجماعـة الرفاق أدواراً ايجابيـة كثيرة لها اهميتهـا في حفظ وضبط سلوك الطلاب، بل ومساعدتهم على التعليم والتحصيل الدراسى، واعدادهم جسمياً وعقلياً وانفعالياً، إلا أن جماعـة الرفـاق لا تقوم بـدور تربـوي إيجـابي في جميـع الأحيـان، وانمـا لجماعة الرفاق وقرنـاء السوء أدوار غير تربويـة من الخطورة بمكان على مستقبل الطلاب وخاصة طلاب التعليم الثانوي الفني.

ويتوقف تأثنر الأصدقاء في الفرد على أخلاقهم وميولهم، وإذا كإنو جماعة لا تحترم القانون ولا تلتزم بالفضـائل فإن تأثنرهم على الفرد يكون تأثنراً سيئًاً في الغالب، وقد 
أسماء حسنى محمود أحمد

تتـخل مـع هـا التأثير ظـروف تجعل الفـرد ينجذب إلى الأصـدقاء مثنل الفشـل في المدرسة والمعاناة من الفقر ، وأثتتت البحوث أن معاشرة أصدقاء السوء تعد من عوامل

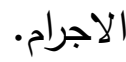

وأجريت دراسات ميدانية على طلاب المدارس بالقاهرة وثبت منها أن 7 0.\% قد تتاولوا المخدرات، وكان من أهم عوامل إدمان المخدرات بين الطلاب تأثنير الثبان الآخرين وإهمـال الأسـرة لـدورها في النصـح والتوجيـه والمراقبـة فضـلاً عـن التفريط في دور المدرسة.

\section{المستحدثات التكنولوجية والجريمة:}

\section{- مبكة الاتصالات الدولية Internet والجريمة:}

لم يكن هناك قلق مع بداية شبكة الإنترنت تجاه الجرائم التي تتم عن طريق الإنترنت

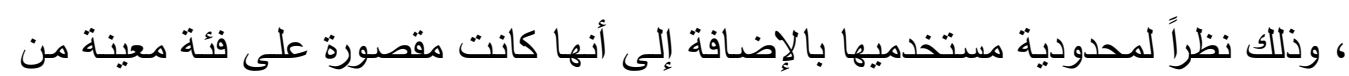
المستخدمين ؛ لكن مـ توسع استخدام الانترنت ودخول جميع فئات المجتمع إلى قائــة المستخدمين حيث أصبح الإنترنت في متتـاول يــ الجميـع ونتيجـة للاستخدام الخاطئ للإنترنت بدأت تظهر جرائم على شبكة الإنترنت وازدادت مـع الوقت وتعددت صـورها وأشكالها .

الانترنت والسلوك الإجرامي : الإنترنت ثقنية تعكس ما سيكون عليه حال البشرية في المستقبل، وهى تتقل الانسان من عصر إلى عصر بسرعة مذهلة لا يمكن للمريء أن يتجاهلها أو يتخلف عنها حتى أن الباحثين والخبراء في الوقت الحالي يتحدثون عن

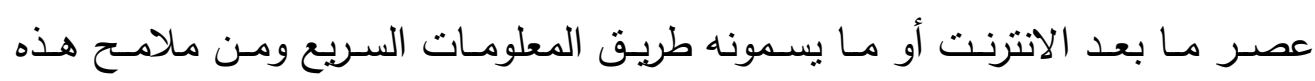
المرحلة كما يرى الخبراء أن المصارف ستكون بـلا صرافين، وقد ظهر ذلك في الوقت الحالي إذ يمكن سـب النقود بطريق البطاقة البلاستيكية من الصـراف الآلي، ويمكن 
أسماء حسنى محمود أحمد

كذلك تحوبل النقود بطريق الإنترنت بمجرد أن تضغط زراً، ومن ملامـح هذه المرحلة كذلك أن تجد المتاجر الافتراضية على الشبكة بدون أرفف، وتظهر صناعة الإعلانات التفاعلية، ويقصد بها التفاعل ما بين طالب السلعة أو الخدمـة، والإعـلان عنها، حتى لقد قيـل أنـه يمكن أن يـرى أو يسـمع أو يتذوق حسـب التي يطلبهـا، وسـوف تتسـب ملامح هذه المرحلة كذللك إلى نشر الكتب، بدون أوراق بالطبع، وسوف تصمم كذلك فكرة الحكومة الإليكترونية. وسوف ينعكس ذلك كله على تعليم الطلاب. وتعلـيم الطـلاب تحديـداً مسـألة غايـة فـي الدقـة والأهميـة والخطـورة مـا لـم تأخـذها الحكومات وأصحاب القرار مأخذ الجد والتخطيط الواعي السليم، ذلك أن الإنترنت رغم مـا يحمله من ايجابيات فإنه ينطوي على العديد من السلبيات في جوانب استخدامه والتي أن ترك الطالب مطلق السراح لها، فسوف تؤثز عليه بطربقة مؤكدة على نحو يفقده القدرة والقدوة في أن يكون عضواً نافعاً في المجنمع. وعند النظر الى الانترنت من زوايا أمنية جنائية، فلا شك أن طبيعة الثبكة التفاعلية يمكن أن تسـهم في تقديم خدمات كبرى للعصـابات الإجراميـة والمنظمات الإرهابية تمكنهم من خلالها من تبادل الاتصسالات والمعلومات واجراء المشـاورات ووضع الخطط في غفلة عن عيون الأمن، وعلى الانترنت أيضـاً تتشر عشرات المواقع للجماعات العرقية والدينيـة المضـطهدة وتشـتخدم بفاعليـة مـن قبـل الكثــر مـن الجماعـات ذات التوجهـات الفكريـة والسياسية للاتصال والتسيق بعد أن ضيقت عليها الأجهزة الرسمية قنوات الاتصال فيما بينهما أو التواصل مع مؤديها. مؤدى ذلك أن الانترنت قد انضمت إلى قائمة الأسباب التي تساهم في جرائم الاحداث من أهم هذه المظاهر ما يلى: ا ـ اختراق أنظمة المعلومات. 
r. الجريمة المنظمة والأحداث.

r. الأحداث وإساءة استخدام البربد الإلكتروني.

ـ. الأحداث والانترنت ونبادل معلومات التطرف والارهاب.

هـ الأحداث وسرقة الأموال وبطاقات الأتثمان بطريق الانترنت.

צ. الأحداث وتهديد الأمن القومي للدول بطرق الإنترنت.

V. الأحداث وأفعال العنف والقتل بطريق الانترنت.

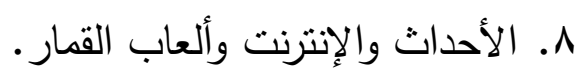

9 ـ الأحداث والإنترنت وتهديدات التجارة الإليكترونية.

• 1 . الأحداث والإنترنت واللهو غير البريء.

11. الأحداث والإنترنت وسرقة الخدمات المعلوماتية (الاتصالات).

إن العصر الذى نعيشه ، والعصر القادم ، هو عصر الإنترنت ، حيث سيطرت فيه

المعلوماتيـة على كل شيء في حياتتـا ، وبقدر التفوق والالمـام بفنونها ، تكون القدرة والسـيطرة ، وبقدر الخضـوع لمسـاوئها ، يكون الهـدم في أجيـال الثـباب التي هي أمـل المستقبل ، والانترنت واقع لا مفر منه ، ولا يمكن التغاضـي عنه أو إصـدار قرار بعدم

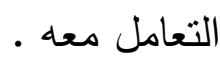

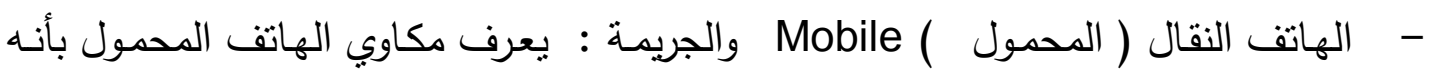
جهاز ارسـال يستخدم موجـات الراديو، وتشـح بوصـول الإشـارة إلى المتلقي في منطقـة جغرافية تسمى الخلية، وحين يتم استقبال الإشارة يتم تحويلها مباشرة إلى شبكة التليفونات المركزبة.

ويُعرف أيضاً على أنه عبارة عن جهاز مستعرض لاسلكي ينقل الصوت والصورة من الهاتف الجوال أو جهاز العرض الرقمي، ويمتاز بأنه عملي وسهل الاستخدام، وهو الأداة 
المناسبة للراغبين في نشارك الصوت والصورة بطريقة سهلة بدون أية صعوبات، ويمكنه نقل الصـوت والصـورة بسـهولة من الهاتف المحمول إلى هـاتف محمول أخر عن طريق لمسة واحدة بسيطة على لوحة المفاتيح، وهو قابل للاستخدام مع الكمبيوتز أو مـع جهاز العرض الرقمي. وفى مقدور الانسـان أن يحمل هاتفه المحمول الى أي مكان يذهب إليه ويمكن استخدامه في أي وقت ومكان اذا ما توافرت الخدمة المطلوبة لتشغيله، ويمكن من خلالـه الدخول الـى شبكة الانترنت والوصـول الى المعلومـات والبيانـات، وتصفح المواقع واستخدام البريد الإكتروني، كما أنه يمناز بصغر حجمه وخفة وزنه. جـرائم الهاتف المحمـول المرتبطـة بطـلاب المدرسـة الثانويـة الفنبـة: لهذه التقنيـة الحديثـة وملحقاتها، والتي أصبحت في متتـاول يد جميع أفراد المجتمع بكافة فئاته تتطوي على العديد من المخاطر الناتجة عن الاستخدام السيئ لهذه التقنية خصوصاً على فئة الأحداث والثباب والمراهقين ومن الافعال الإجرامية التي ترتكب من خلال تقنية الهاتف المحمول، ومـن أخطرهـا اسـتخدامه في الامـور غبر الأخلاقيـة مـن قبـل بعض الثباب والأحـداث والمتمتلة في المعاكسات الهاتفية، وتبادل الرسائل المكتوبة غير اللائقة والرسائل المصورة للفتيات ، وارسـالها بتقنيـة البلوتوث وبرسـائل الوسـائط المتعددة والمخلـة بـالآداب ، ونشـرها بين الثباب وتبادل مقاطع الفيديو الإباحية في الأماكن العامة. وهناك العديد من الأفعال السلبية التي ترتكب من قبل الأحداث من خـلال استخدامهم لتقنية الهاتف الجوال والتي يمكن أن نجملها فيما يلى:

$$
\begin{aligned}
& \text { 1- الجرائم الأخلاقية: } \\
& \text { r- التهديد والابتزاز : } \\
& \text { r-السب والقذف }
\end{aligned}
$$

ع - نشر الفيروسات وتخريب الهواتف النقالة 
0- سرقة الملفات والمعلومات والصور المخزنة على الجهاز 7- إثاعة الفوضى داخل الجهاز V- نقل الثائعات r- التقليد والمحاكاة

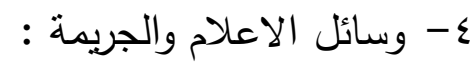

أصبح مؤكداً أن هناك اتفاق عام بين المختصين على ان تكنولوجيا التخزين والاسترجاع تشكل مـع تكنولوجيـا الاتصـال الحديثة، وتكنولوجيـا الاعـلام تعنى تكنولوجيـا الاتصـال، والأخيرة أصبحت تمثنل العمود الفقري للعمـل الإعلامس، ولهذا وذاك ، فإن أمـر دراسـة تأثثر الجانب السلبى( المخاطر الاعلامية) لتكنولوجيا الاعلام بات ضرورياً، بل أمراً لابد منه.

يكاد يكون هنـاك إجمـاع على إن الإعـلام في العصـر الراهن أصبح يحتل مكانـه حيوية، بل رئيسية بين وسائل الحياه المتعددة في عالمنا المعاصر ، بل بمكن القول: إن وسائل وأنشطة الحياه الآن، كالتعليم والصحة والصناعة والتجارة، تعتمد اعتمـاداً رئيسياً على الأعلام لتيسيرها ورواجها. وإذا شئنا أن نتصـور حجم هذه الأهميـة، فيمكنـا تخيل حال المجتمعات المعاصرة بغير أعلام، فلا يوجد الآن مجتمع متقدم أو نام يمكنه مواجهة المنطلبات المعاصرة من النمو والتتوع بغير وسائل اتصال مؤثرة وسريعة ومنتوعة.

تتبع خطورة المد المعلوماتي الجديد من قدرته على استحواذه على القنوات والأدوات التي تصنع ثقافة الفرد وبالتالي تستحوذ على بنيته المعرفية وتتحكم في سلوكه وتوجهاته وأهدافه، وبعبارة موجزه فإنها تسترقه في القطيع الإلكتروني التي يقوده قلة ونخبة تستحوذ على معظم موارد العالم ، والثورة المعلوماتيـة هي من أخطر التحديات والأعاصير التي تهب علينـا وتجتاحنـا مـن جذورنا لتقيدنا في زنزاناتها الإعلاميـة والتقنيـة وتغسـل عقولنـا 


\section{أبعاد الجريمة فى التعليم الثانوي الفني}

\section{/أسماء حسنى محمود أحمد}

بإعلاناتها وتأثيراتها الضوئية المبهرة حتى تمحى صورنا المعرفيـة الأصيلة وتؤسس في أعماق حضارتتا معرفتها الهزيلة القائمة على المادة واللهو والأنانية.

وبشكل عم اتهمت وسائل الاعلام المختلفة بأنها مسؤولة عن:

$$
\text { ا ـ تـور مستوى الذوق النقافي العام. }
$$

r · زيادة معدلات اللامبالاة والميل إلى انتهاك القانون. r. المساهمة في الانهيار الأخلاقي العام. ـ ـ تشجيع الجماهير على السلطة السياسية.

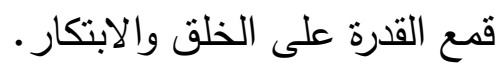

ه. تعلم الأفراد أسـاليب جديدة لارتكاب الجـرائم، وخير مثنال على ذلك هو مـا تتشـره الصحف بين حين وآخر عن أحدث الوسـائل الفنيـة لسرقة السيارات، وكيفيـة تغيير معالم ملكيتها الحقيقيـة، وطرق تزويـر وثائق تسـجيلها إلى غير ذلك مـن الوسـائل المستخدمة في عالم الجريمة. 7. قد يجعلها حدثاً مألوفاً بالنسبة للقارئ، وفى ذلك الضرر مالا يخفى. V. تقوم بعض وسـائل الاعـلام بإظهـار جدوى الجريمـة في نهايـة المطـاف فهي تبرز أحياناً كيف يعيش بعض المجرمين المحترفين، وكيف يسرفون في متع الحياه. ^. تميل بعض وسائل الاعلام الى اظهار المجرم في صورة البطل الأمر الذى يجعل منـه نموذجـاً حيـاً لأكثر مـن طفـل أو مراهـق أو بـالغ، وتصـبح بالمقابـل الأجهـزة المختصة بملاحقة المجرم محل سخرية واستهزاء. 9. تعيـق بعض وسـائل عمـل الأجهزة المختصــة مـن خـلال مـا تتشـره عـن الخطـط والتحقيقات فتفسد عملها وتسدى بغير قصد إلى المجرمين خدمة كبرى. 


$$
\text { أبعاد الجريمة فى التعليم الثانوي القني }
$$

أسماء حسنى محمود أحمد

•1. تسهل أحيانـا بعض وسـائل الإعـلام فكرة الجريمـة أو وسيلة تنفذها أو أسلوب إخفائها.

11. تثير بعض الغرائز والرغبات الكافة في نفوس بعض المراهقين وكذلك الكبار لاسيما المنحرفين.

يتضـح ممـا سبق، إن التحدي المطروح على السـاحة العالميـة اليوم، ونحن نعيش

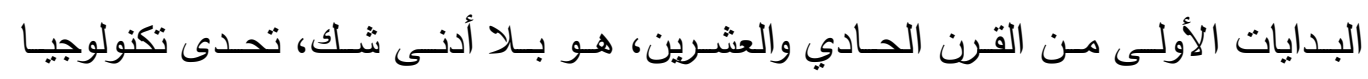

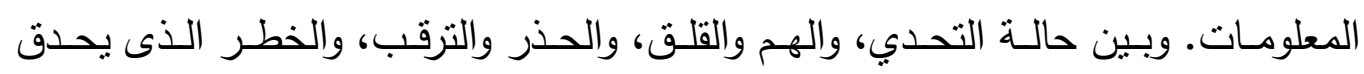

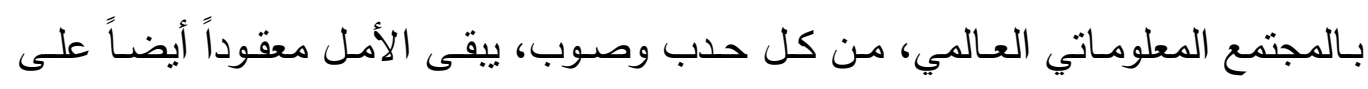

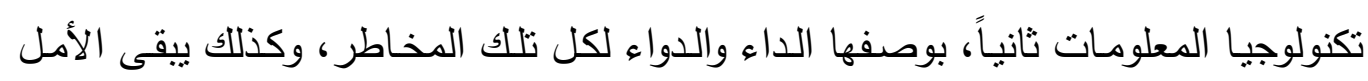
معقوداً على مستخدمي هذه التكنولوجيا، في رسم إثراقة غد أفضل وخير أوفر، للإنسانية جميعاً. 
1. إسماعيل بن وصفى غانم الأغا(9 . . ץ): سوء استخدام تقنية الإنترنت والجوال

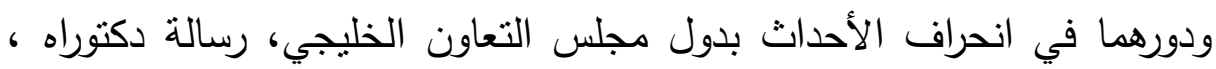

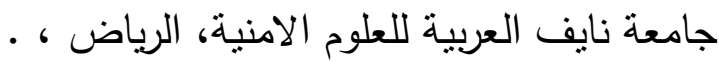

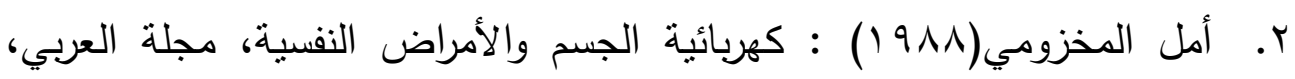
الكويت.

r. الأمم المتحدة، المجلس الاقتصادي والاجتماعي، لجنة منع الجريمة ومكافحتها،

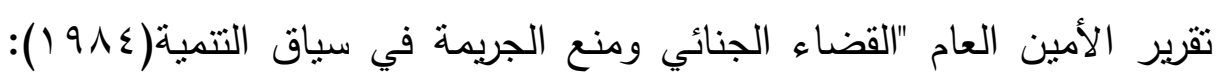
العلاقة بين الجريمة ومسائل اقتصادية اجتماعية محددة" ، الدورة الثامنة، فيينا،.

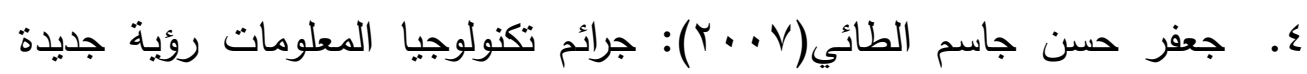

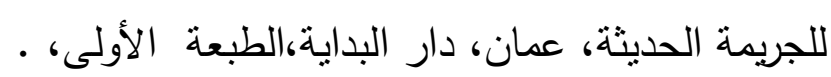

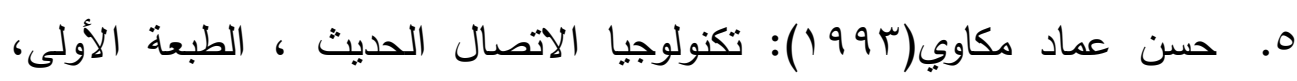

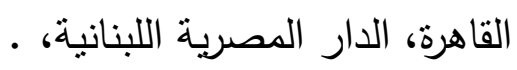

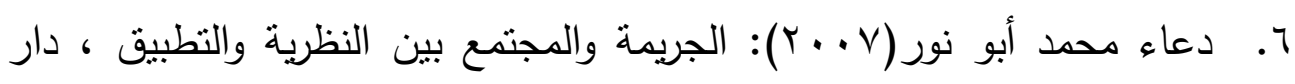

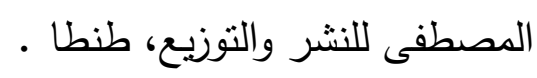
V. ساندرا بول واخرون(999 (1): نظريات وسائل الاتصال، ترجمة كمال

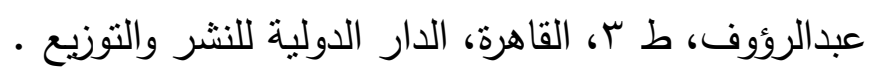

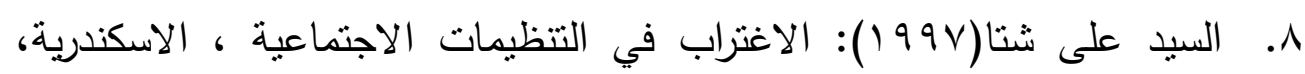
مكتبة الإشعاع

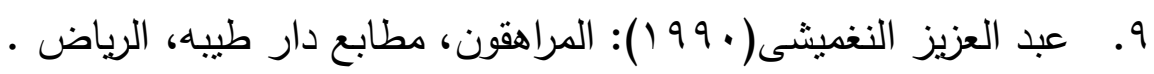

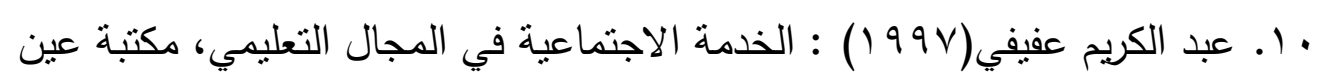

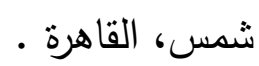
11 . . عبدالرحمن محمد أبو توته( 999 (1): علم الإجرام، بيروت، . 
/أسماء حسنى محمود أحمد

Y I. عبدالرحمن محمد مفرح الثهراني(؟ . . Y): الخصائص الاجتماعية لمرتكبي جريمة سرقة المحلات التجارية،رسالة ماجستير، جامعة نايف العربية للعلوم

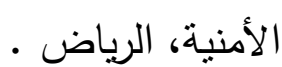

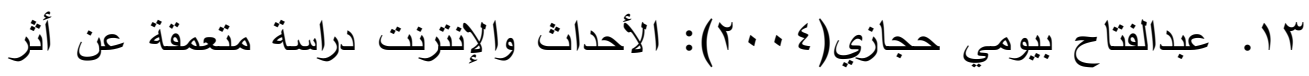
الإنترنت في انحراف الأحداث، دار الفكر الجامعي، الاسكندرية .

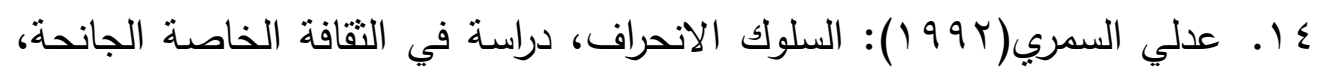

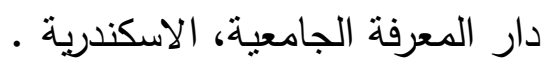
1. . عمرو أحمد حسبو ( . . †): حماية الحريات في مواجهة نظم المعلومات، دار النهضة العربية، القاهرة . ا ـ . فايز الثهري( ( . ب): الإعلام الإلكتروني والأمني في ندوة الأمن والحياة، مجلة الأمن والحياة، ع r ع r الرياض، اكاديمية نايف العربية للعلوم الأمنية .

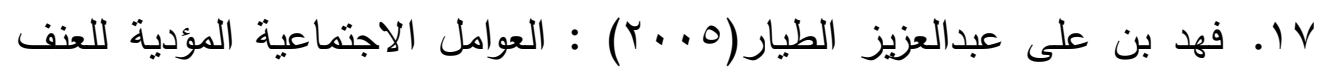

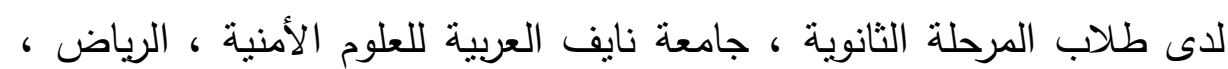
المملكة العربية السعودية . 1 ا. ماجد بن جبران صلوى (V . . r): الآثار الاجتماعية لاستخدامات الهاتف الجوال

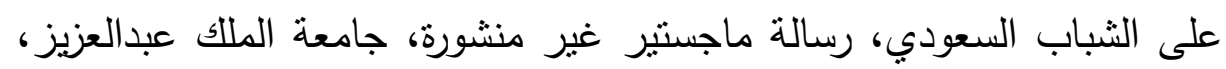
جدة. 9 1. مجدى أحمد عبد الله (9 . . ب): السلوك الإجرامي ودينامياته ، دار المعرفة الجامعية. •r. كحسن السيد (I) إه): "دور التربية في وقاية طلاب المرحلة الثانوية من المخدرات" المركز الحكومي للبحوث التربوية والتتمية ، القاهرة .

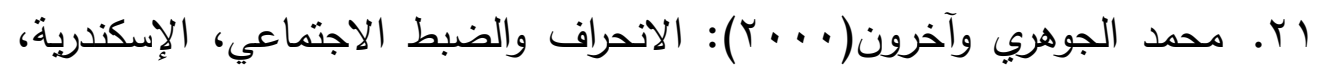

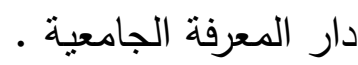


r r. محمد الصالح العريني : دور مدير المدرسة في الحد من عنف الطلاب في المدارس بالمملكة العربية السعودية ، دراسة نطبيقية على مديري المدارس بمدينة الرياض ، رسالة دكتوراه غير منشورة ، جامعة السودان للعلوم والتكنولوجيا .

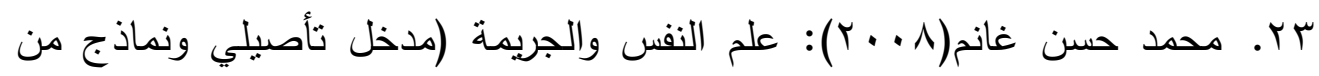

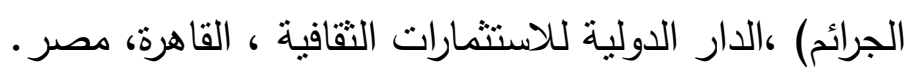

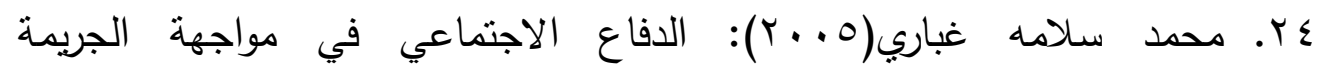
والانحراف، دار المعرفة الجامعية، الإسكندرية .

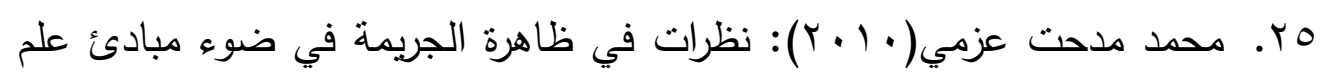

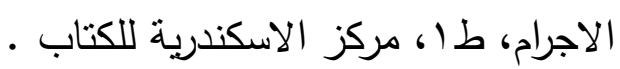

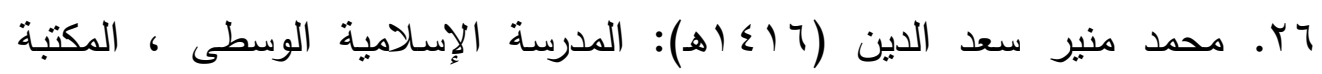

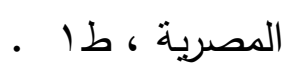

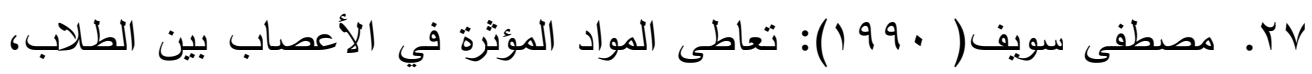
المجلد الأول، المركز القومي للبحوث الاجتماعية والجنائية، القاهرة.

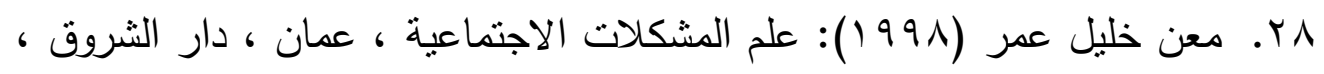
. I 9. . مقداد يالجن(1991): منابع مشكلات الأمة الإسلامية والعالم المعاصر ودور

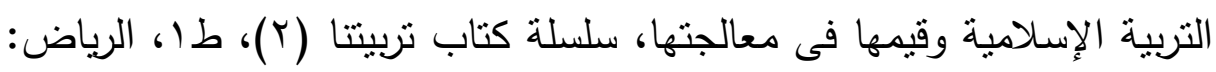

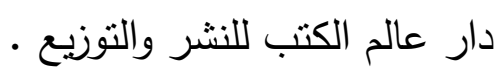
•r. نجاة السنوسي (Y0) (هـ): الأثر الذى يولده العنف على الأطفال ودور

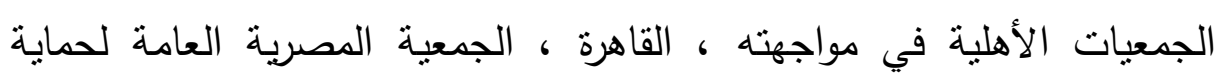

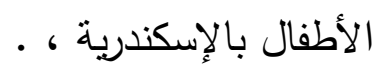

